\title{
ADAPTAÇÃO DE MATERIAIS/RECURSOS NA EDUCAÇÃO DE SURDOS: UMA REVISÃO BIBLIOGRÁFICA
}

\author{
ADAPTACIÓN DE MATERIALES/RECURSOS EN LA EDUCACIÓN \\ DEL SORDOS: UNA REVISIÓN BIBLIOGRÁFICA
}

\section{ADAPTATION OF MATERIALS/RESOURCES IN EDUCATION OF DEAF: A BIBLIOGRAPHIC REVIEW}

\author{
LARISSA DA COSTA \\ Universidade Federal de São Carlos. \\ Lara Ferreira dos Santos
}

Universidade Federal de São Carlos. FAPESP Proc. 2017/16776-9.

\begin{abstract}
Resumo O presente estudo visou analisar os materiais e conteúdos pedagógicos pensados para alunos surdos em contexto de educação inclusiva bilíngue, tendo em vista identificar quais estratégias e materiais didáticos são atualmente utilizados e disponibilizados para esses alunos. Este trabalho se justifica por pretender uma revisão e análise sobre as mudanças que vêm sendo propostas na educação para atender às especificidades desse alunado, a partir da publicação do Decreto 5.626, do ano de 2005. Realizou-se um levantamento bibliográfico efetuado nos periódicos Portal de Periódicos CAPES e Scielo, em um período de doze anos, de 2005 a 2017. Os dados revelaram que há pouquíssimos resultados; acredita-se que muito se tem discutido acerca de questões como a educação inclusiva, e materiais e/ ou recursos adaptados, entretanto, quando relacionados à temática surdez, tais registros se tornam bastante escassos. Com a vigência do Decreto 5.626, a Libras passou a ter maior relevância nas adaptações feitas, bem como, na produção de softwares que atendam a alunos com deficiência. Todavia, apenas inserir a Libras como forma de "adaptação" de materiais é insuficiente, pois esta, obrigatoriamente, deve ser o principal meio de acessibilidade.

Palavras-chave: Educação Bilíngue; Educação de surdos; Educação Especial; CurrícuLo Adaptado; Surdez.
\end{abstract}


RESUMEN El presente estudio tuvo como objetivo analizar los materiales y contenidos pedagógicos pensados para alumnos sordos en contexto de educación inclusiva bilingüe, buscando identificar qué estrategias y materiales didácticos son actualmente utilizados y puestos a disposición para estos alumnos. Este estudio se justifica por pretender una revisión y análisis sobre los cambios que vienen siendo propuestos en la educación para atender las especificidades de este alumnado a partir de la publicación del Decreto 5.626 del año 2005. Se realizó un levantamiento bibliográfico realizado en los periódicos Portal de Periódicos CAPES y Scielo, en el período de doce años, de 2005 a 2017. Los datos revelaron que hay poquísimos resultados; se cree que mucho se ha discutido sobre cuestiones como la educación inclusiva, y materiales y / o recursos adaptados, sin embargo, cuando relacionados con la temática sordera, tales registros se vuelven bastante escasos. Con la vigencia del Decreto 5.626, la Libras pasó a tener mayor relevancia en las adaptaciones realizadas, así como en la producción de softwares que atiendan a alumnos con discapacidad. Sin embargo, sólo insertar la Libras como forma de "adaptación" de materiales es insuficiente, pues ésta, obligatoriamente, debe ser el principal medio de accesibilidad.

Palabras clave: Educación bilingüe; Educación de sordos; Educación Especial; Currículo AdAPTAdo; Sordera.

Abstract The present study aimed to analyze the materials and pedagogical contents designed for deaf students in the context of bilingual inclusive education, in order to identify which strategies and didactic materials are currently used and made available to these students. This research is justified by a review and analysis of the changes that have been proposed in education to meet the specific characteristics of this student, since the publication of Decree 5.626, of the year 2005. A bibliographic research was carried out in the periodicals Portal of CAPES and Scielo periodicals, in the period of twelve years, from 2005 to 2017. The data revealed that there are very few results; it is believed that much has been discussed on issues such as inclusive education, and materials and / or adapted resources, however, when related to the theme deafness, such records become rather scarce. With the implementation of Decree 5.626, Libras became more relevant in the adaptations made, as well, as in the production of software that attend students with disabilities. However, only inserting Libras as a form of "adaptation" of materials is insufficient, since it must necessarily be the main means of accessibility.

Keywords: Bilingual Education; Education of the deaf; Special education; Adapted Curriculum; Deafness.

\section{INTRODUÇÃo}

A Educação Especial tem sido tema de grandes discussões e abordagens, as quais passam por constantes transformações, cedendo espaço cada vez mais às novas políticas de inclusão e valorização do deficiente - embora sua trajetória tenha sido marcada por grande descaso e preconceito. 
Após décadas de grandes entraves e lutas por mais direitos e condições, as pessoas com deficiência conseguiram estabelecer à sociedade sua cidadania até então negada, de modo que esta passou a discutir sobre suas necessidades e encaminhamentos necessários para a oferta de uma educação de qualidade. Com o passar do tempo, discussões referentes aos direitos e deveres desses indivíduos começaram a ganhar espaço e, assim, a preocupação em ofertar atendimento adequado despertou o interesse pela criação de instituições educacionais voltadas a esse público.

Com esse interesse, surgiram também movimentos que promoveram a sistematização de políticas de inclusão social e educacional. A declaração de Salamanca (BRASIL, 1994), possibilitou que tais sistematizações fossem reafirmadas, assegurando às pessoas com deficiência o direito à educação de qualidade, bem como, o direito às condições básicas de aprendizagem e interação social. Atualmente, compreende-se que a educação deve ser voltada para a formação de cidadãos críticos e participantes, cientes de seus deveres e direitos. Ou seja, o enfoque não é educar para reproduzir ensinamentos, mas sim, educar para criar, para crescer e aprender a aprender.

A política educacional vigente no país preconiza a inclusão de todas as crianças na escola regular, sejam estas com deficiência ou não. De acordo com a Lei $n^{\circ} .13 .146$ (BRASIL, 2015), a inclusão da Pessoa com Deficiência é "destinada a assegurar e a promover, em condições de igualdade, o exercício dos direitos e das liberdades fundamentais por pessoa com deficiência, visando à sua inclusão social e cidadania". De acordo com Freire (2008, p. 5):

\footnotetext{
A inclusão é um movimento educacional, mas também social e político que vem defender o direito de todos os indivíduos participarem, de uma forma consciente e responsável, na sociedade de que fazem parte, e de serem aceitos e respeitados naquilo que os diferencia dos outros.
}

Portanto, cabe à escola e aos órgãos gestores desenvolver métodos e estratégias que garantam não só o acesso ao ambiente educacional, como também o acesso aos conteúdos curriculares, de modo que alunos com deficiência compreendam e aprendam, com possibilidades de interações com os pares e vivências de novas experiências, a fim de complementar o contexto e a leitura de mundo dos alunos.

Com a municipalização do ensino fundamental, em 1995, a Secretaria de Educação Especial (SEESP) do Ministério da Educação e do Desporto (BRASIL, 2001a) passou a defender que $\mathrm{o}$ atendimento de alunos com deficiência fosse assumido pelas prefeituras, a fim de garantir sua aprendizagem e desenvolvimento. No entanto, garantir escolas para todos se mostra insuficiente; é necessário assegurar que a educação seja efetiva em seus princípios. Prieto (2002, p. 4) afirma que: "A inclusão escolar e social deve ser compreendida como educação de qualidade para todos e não somente como acesso de alunos com necessidades educacionais especiais na rede regular de ensino". Portanto, compreende-se que o sentido de inclusão não se resume ao acesso, mas também à permanência de qualidade desses educandos no ensino regular, que é primordial. 
Quando se trata de alunos com surdez, a questão educacional se mostra de extrema complexidade. Deve-se oferecer igualdade de oportunidades, atender às necessidades individuais de cada aluno, garantir acesso (social e aos conhecimentos) e permanência - e, ainda, considerar que o aluno surdo é o único (entre as demais deficiências e diante da comunidade escolar) que utiliza uma língua diferente da usada pela maioria, a Língua Brasileira de Sinais - Libras.

Diante dessa problemática, este trabalho visa analisar materiais pedagógicos adaptados existentes/ofertados atualmente para os alunos surdos, bem como, quais as adaptações curriculares realizadas a fim de promover acessibilidade ao conhecimento e auxiliar o processo de ensino e aprendizagem desses alunos.

\section{A eduCaÇão de surdos na ATUALidade}

A educação de surdos tem se caracterizado por embates e conflitos motivados, especialmente, por diferentes concepções de surdez e de língua(gem) que, a cada tempo, ganham novas roupagens e significações, uma vez que as línguas são vivas, e sofrem constantes modificações. Por um lado, tem-se o conceito clínico/médico, que visa quantificar a perda auditiva e promover a "cura" - e que, com frequência, orienta muitas das ações educacionais; por outro, a visão socioantropológica, que compreende o indivíduo surdo como um ser pertencente de sua cultura, porém "diferente". Assumimos na presente pesquisa a segunda concepção, pois consideramos a surdez, como aponta Skliar (2005), como diferença (e não como deficiência); e tal diferença se dá não pela ausência de audição, mas pelo desenvolvimento de potencialidades psicológicas - distintas daquelas produzidas por pessoas ouvintes -, que se pautam na linguagem e na visualidade.

Seguindo esses mesmos preceitos, Wrigley (1996 apud SÁ, 2001) aponta que a pessoa surda constrói sua identidade assentada principalmente na diferença, utilizando estratégias cognitivas e de manifestações comportamentais e culturais visuais diferentes das pessoas que ouvem. Nesse sentido, o difícil acesso à língua majoritária oral ocasiona defasagens no processo de aprendizagem, sendo de suma importância desenvolver práticas pedagógicas que atendam às necessidades desses alunos. Para que essas práticas pedagógicas sejam acessíveis e façam sentido ao aluno surdo, é necessário que lhe seja propiciada a aquisição e o uso da Libras no espaço escolar. Freire (2008, p. 33) aponta que a partir de "uma proposta bem fundamentada teoricamente, é possível reverter o quadro de apatia e fracasso em que parece estar mergulhada a educação dos surdos". E menciona ainda que "esta proposta leva em conta as necessidades sociais, intelectuais, profissionais, e os interesses/desejos dos aprendizes".

A Língua Brasileira de Sinais - Libras, é reconhecida oficialmente como meio legal de comunicação e expressão das comunidades de pessoas surdas (BRASIL, 2002). É considerada também como língua de aquisição natural, enquanto a língua portuguesa, na modalidade escrita, é a língua de aprendizagem sistemática, conceituada como segunda língua para aqueles que têm a Libras como primeira língua. 
Todavia, a Libras, embora oficializada, segue desconhecida pela maioria da sociedade e, à semelhança de outros idiomas minoritários como as diversas línguas indígenas, não possui prestígio social e sua utilização permanece restrita a segmentos em que haja a aglutinação de pessoas surdas como: associações, escolas especiais, pastorais e ministérios, se considerarmos as formas de organização de igrejas católicas e evangélicas, respectivamente. Ainda que a Libras seja reconhecida no ambiente educacional, a presença da língua portuguesa oral e escrita predomina, conforme apontam Lacerda e Lodi (2012). As autoras defendem um modelo de educação bilíngue em que os surdos possam ter contato o mais precocemente possível com a Libras, língua que lhes é acessível e não carece de qualquer estratégia para ser ensinada. Ao contemplar o direito linguístico das pessoas surdas, se proporciona também o contato com diferentes interlocutores, com aspectos culturais e identitários, e o acesso aos conhecimentos que serão a base para todo seu aprendizado ao longo do percurso acadêmico. Posto isso, tal proposta defende ainda o ensino do português como segunda língua, sendo esta adquirida por meio dos conhecimentos em Libras. Dessa forma, e contando com a presença de profissionais capacitados para esse novo modelo de educação, o surdo poderá circular livremente nesses dois "mundos" - o dos surdos e o dos ouvintes.

Deste modo, a partir do conceito de bilinguismo para surdos, compreende-se que todo sujeito surdo tem o direito de aprender a língua portuguesa como segunda língua, na modalidade escrita, e se tornar bilíngue de fato; esse é um direito assegurado pelo Decreto $\mathrm{n}^{\circ}$. 5.626 (BRASIL, 2005). O mesmo Decreto aponta que a Educação Bilíngue para surdos deve se configurar da seguinte maneira:

Artigo 22. As instituições federais de ensino responsáveis pela educação básica devem garantir a inclusão de alunos surdos ou com deficiência auditiva, por meio da organização de:

I - Escolas e classes de educação bilíngue, abertas a alunos surdos e ouvintes, com professores bilíngues, na educação infantil e nos anos iniciais do ensino fundamental;

II - Escolas bilíngues ou escolas comuns da rede regular de ensino, abertas a alunos surdos e ouvintes, para os anos finais do ensino fundamental, ensino médio ou educação profissional, com docentes das diferentes áreas do conhecimento, cientes da singularidade linguística dos alunos surdos, bem como com a presença de tradutores e intérpretes de Libras - Língua Portuguesa.

§ 1ํㅗ̃o denominadas escolas ou classes de educação bilíngue aquelas em que a Libras e a modalidade escrita da Língua Portuguesa sejam línguas de instrução utilizadas no desenvolvimento de todo o processo educativo.

O Decreto garante ainda, nos anos finais do Ensino Fundamental, a presença de docentes de diferentes áreas do conhecimento, cientes da singularidade linguística dos alunos surdos. Esse perfil esperado para os docentes visa a possibilidade de ministrarem aulas adequadas metodologicamente e conhecimento mínimo das condições do aluno surdo acreditando que esse profissional, conforme também prevê o Decreto, tenha cursado a disciplina de Libras obrigatória (BRASIL, 2005): 
Artigo 3- A Libras deve ser inserida como disciplina curricular obrigatória nos cursos de formação de professores para o exercício do magistério, em nível médio e superior, e nos cursos de Fonoaudiologia, de instituições de ensino, públicas e privadas, do sistema federal de ensino e dos sistemas de ensino dos Estados, do Distrito Federal e dos Municípios.

$\S 1$ o Todos os cursos de licenciatura, nas diferentes áreas do conhecimento, o curso normal de nível médio, o curso normal superior, o curso de Pedagogia e o curso de Educação Especial são considerados cursos de formação de professores e profissionais da educação para o exercício do magistério.

O mesmo Decreto orienta sobre a obrigatoriedade da presença de tradutores e intérpretes de Libras - Língua Portuguesa (TILS) a partir dos anos finais do Ensino Fundamental. De acordo com a Lei 12.319 (BRASIL, 2010), esse profissional é responsável por realizar a tradução e interpretação das duas línguas - Libras e Português - de maneira simultânea ou consecutiva. Assim sendo, nas escolas com propostas de educação bilíngue são inseridos na sala de aula TILS, ${ }^{1}$ possibilitando que os alunos surdos tenham acesso a todas as informações que circulam nesse espaço.

Ao inserir em sala de aula um TILS, se possibilita que o aluno surdo receba as informações e conteúdos escolares em Libras, por meio de uma pessoa com competência nessas línguas. No entanto, a presença do TILS pode não significar a solução de todos os desafios. Lacerda (2002, p. 128) expõe que "a presença do intérprete em sala de aula e o uso da língua de sinais não garantem que as condições específicas de surdez sejam contempladas e respeitadas nas atividades pedagógicas". Assim, a presença do TILS não garante que sejam realizadas adequações em conteúdo, nem mesmo adaptações dos currículos escolares - e esta nem é sua função. O responsável pelos processos de ensino e aprendizagem é o professor, e para atender às demandas e necessidades específicas dos alunos surdos, é necessário que tenha formação condizente, desenvolva metodologia adequada, e compreenda que os processos de aprendizado do aluno surdo diferem dos alunos ouvintes.

\section{O PROFESSOR E O SEU TRABALHO EM SALA DE AULA}

Além do direito de acesso aos conteúdos em sua primeira língua, o Decreto 5.626 aponta, em seu artigo $14^{\circ}$. (BRASIL, 2005), quanto aos anos finais do Ensino Fundamental, que as instituições devem:

III - prover as escolas com:

a) professor de Libras ou instrutor de Libras;

b) tradutor e intérprete de Libras - Língua Portuguesa;

c) professor para o ensino de Língua Portuguesa como segunda língua para pessoas surdas; $\mathrm{e}$

d) professor regente de classe com conhecimento acerca da singularidade linguística manifestada pelos alunos surdos (grifos das autoras).

1 O termo Tradutor e Intérprete de Libras e Língua Portuguesa é referido nos documentos legais pela sigla TILS, que utilizaremos no presente trabalho. 
A presença do aluno surdo em sala exige que o professor reconheça a necessidade da elaboração de novas estratégias e métodos de ensino que sejam adequados à forma de aprendizagem desse aluno. Lacerda et al. (2013) abordam as necessidades formativas dos docentes e de uso de metodologia adequada pelos mesmos, bem como a importância de um conhecimento básico da Libras, visando que o aluno surdo compreenda, de fato, os conteúdos propostos. Ressaltam que uma aula bem preparada favorece não apenas os alunos surdos, mas os ouvintes também:

[...] não basta apenas dominar a língua se não existir uma metodologia adequada para apoiar o que se está explanando, o que incide na necessidade de formação de futuros professores que saibam elaborar boas aulas - visualmente claras e que facilitem a atuação do intérprete e a compreensão do aluno surdo. Esse tipo de formação só tem a contribuir com o aprendizado dos alunos, sejam eles surdos ou ouvintes; uma boa apresentação de slides, por exemplo, é fundamental para alunos ouvintes, e para os alunos surdos esse recurso pode se tornar essencial (LACERDA et al. 2013, p. 191).

No que se refere à importância da formação e capacitação dos professores, Silva (2016) aponta a falta de disponibilidade de tempo dos docentes para se capacitarem, bem como, as consequências no ensino:

Pode-se perceber que um dos maiores entraves no que diz respeito às metodologias para atender aos alunos surdos é a questão disponibilidade de tempo do professor. Assim como também a falta do conhecimento aprofundado da língua de sinais, sendo necessário um momento de estudo, para que haja o repasse de sugestões de metodologias. Pois a falta de recursos e a indisponibilidade de alguns professores a se capacitarem, às vezes acaba por prejudicar a boa qualidade de aprendizagem, principalmente no que diz respeito às provas e atividades em classe (SILVA, 2016, p. 4).

Não se trata apenas de apontar as dificuldades em relação à formação de professores, mas sim salientar o quão importante é a formação desses professores, principalmente na perspectiva de educação bilíngue. Desse modo, todo o processo de formação de docentes, independentemente da área de atuação, tem que ser realizado com dedicação.

Além da questão da formação docente e de metodologias de ensino condizentes com esse alunado, o Decreto 5.626 traz outras informações relevantes quanto ao desempenho do professor regente, no mesmo artigo $14^{\circ}$. (BRASIL, 2005), que deve:

VI - Adotar mecanismos de avaliação coerentes com aprendizado de segunda língua, na correção das provas escritas, valorizando o aspecto semântico e reconhecendo a singularidade linguística manifestada no aspecto formal da Língua Portuguesa;

VII - desenvolver e adotar mecanismos alternativos para a avaliação de conhecimentos expressos em Libras, desde que devidamente registrados em vídeo ou em outros meios eletrônicos e tecnológicos; 
VIII - disponibilizar equipamentos, acesso às novas tecnologias de informação e comunicação, bem como, recursos didáticos para apoiar a educação de alunos surdos ou com deficiência auditiva.

Compreende-se, portanto, que para uma educação bilíngue de qualidade para surdos, deve-se contar com a presença de professores surdos, TILS, professores regentes com formação adequada. Espera-se desse docente que prepare aulas que privilegiem os recursos visuais, que utilize estratégias que favoreçam o uso da Libras pelos alunos, que adote mecanismos avaliativos considerando o português como segunda língua dos surdos.

Isso posto, discutiremos a seguir a importância e a necessidade de um currículo pensado para esse alunado, bem como, os tipos de materiais ofertados na atualidade - aspectos de extrema relevância quando se pretende oferecer igualdade de oportunidade e acesso ao conhecimento para alunos surdos.

\section{Currículo adaptado}

Antes de iniciarmos esta discussão, faz-se necessário compreender os referidos conceitos, uma vez que currículo adaptado difere de material adaptado. Os Parâmetros Curriculares Nacionais (BRASIL, 1997) abordam esse assunto, trazendo a definição de adaptações curriculares como:

[...] possibilidades educacionais de atuar frente às dificuldades de aprendizagem dos alunos. Pressupõem que se realize a adaptação do currículo regular, quando necessário, para torná-lo apropriado às peculiaridades dos alunos com necessidades especiais. Não um novo currículo, mas um currículo dinâmico, alterável, passível de ampliação, para que atenda realmente a todos os educandos. Nessas circunstâncias, as adaptações curriculares implicam a planificação pedagógica e as ações docentes fundamentadas em critérios que definem o que o aluno deve aprender; como e quando aprender; que formas de organização do ensino são mais eficientes para o processo de aprendizagem; como e quando avaliar o aluno (p. 33).

Todavia, para que haja um currículo adaptado é necessário preexistir um currículo; assim, é necessário compreender que há diversas definições de currículo, e que estas perpassam por teorias tradicionais, críticas e pós-críticas, as quais não serão aprofundadas nesta pesquisa. Entretanto, é válido destacar que em qualquer teoria é essencial saber qual conhecimento deve ser ensinado e justificar a escolha dos mesmos.

De acordo com Jesus (s/d., p. 2.639), "o currículo escolar tem ação direta ou indireta na formação e desenvolvimento do aluno. Assim, é fácil perceber que a ideologia, cultura e poder nele configurados são determinantes no resultado educacional que se produzirá". Complementa ainda que o currículo segue paralelamente com a cultura, tornando-os inseparáveis, de modo que este se encarregue de transmitir a cultura de uma sociedade. 
Nesse sentido, é importantíssimo estabelecer uma relação entre o currículo - sendo este carregado de cultura - e o currículo adaptado no contexto educacional do aluno surdo, onde este também deve estar inserido em uma cultura com a qual o aluno surdo se identifique, atendendo não só às individualidades de ensino como também seu desenvolvimento num contexto cultural.

O material, por sua vez, é o recurso pelo qual os conhecimentos do currículo serão transmitidos, ou seja, é por meio dos materiais que todas as informações a respeito da cultura e conteúdos responsáveis pela formação do indivíduo serão ensinadas. Não diferindo, portanto, da definição de material adaptado.

Compreendemos que para ofertar educação de qualidade e em igualdade aos demais alunos (ouvintes e/ou não deficientes), o ideal seria a construção de um currículo voltado para o alunado surdo, atento às peculiaridades de seu desenvolvimento e, principalmente, à sua língua de instrução. Todavia, sabe-se que esta não é uma realidade comum nas escolas inclusivas (salvo algumas exceções, como a experiência trazida por Lacerda e Lodi, 2012), e que a adaptação de um material já traria inúmeros benefícios ao seu desenvolvimento. É a partir dessa realidade escolar que faremos nossas considerações.

Como já apontado, alunos com deficiência, bem como, os alunos surdos, requerem o uso de material e currículo adaptado, que atendam às suas demandas e especificidades. De acordo com Franco (2007), "as adaptações curriculares, de planejamento, objetivos, atividades e formas de avaliação, no currículo como um todo, ou em aspectos dele, são para acomodar os alunos com necessidades especiais...", ou seja, servem para propiciar ao aluno com deficiência equiparidade e aprendizagem do conteúdo a ser ensinado.

Tem sido crescente a frequência de alunos surdos nas escolas regulares, em classes de alunos ouvintes (MELETTI; BUENO, 2010), o que, por sua vez, torna indispensável a necessidade de um currículo pensado e elaborado de forma a atender a heterogeneidade das salas de aula. Todavia, esses alunos são tratados com um tipo de "igualdade" desfavorável, no sentido de que devem acompanhar os conteúdos sem que haja qualquer alteração no currículo ou na metodologia de ensino, e que propiciem condições reais para o seu aprendizado (LACERDA, s/d).

Nesse sentido:

[...] políticas de Educação Especial voltadas ao alunado surdo são fundamentais porque suas dificuldades de aprendizagem não são inerentes à condição de surdez. Em geral são secundárias a práticas pedagógicas equivocadas, com propostas educacionais que embora tenham como objetivo proporcionar o seu desenvolvimento pleno têm lhes causado uma série de limitações [...] (LACERDA, s/d, p. 3).

A autora aponta ainda que, ao desconsiderar a condição linguística do aluno surdo, as instituições de ensino (e os professores) insistem em utilizar as mesmas estratégias e metodologias de ensino elaboradas para alunos ouvintes, e que tais abordagens têm apresentado resultados pouco satisfatórios no ensino e aprendizagem desses alunos. 
Formoso (2009, p. 35) nos diz que é de extrema valia "proporcionar à criança surda, o mais cedo possível, o contato com a língua de sinais, pois é através dessa língua que ela construirá sua identidade surda, inserindo-se dessa forma, na comunidade surda e partilhando as experiências culturais surdas". Desse modo, para incluir o aluno surdo é necessário propiciar um currículo pensado e elaborado, de modo a favorecer a aquisição da língua de sinais anteriormente ao ensino da Língua Portuguesa, a fim de imergi-lo na cultura surda de modo natural e familiar; a partir dos conhecimentos fundamentais em sua língua natural ou mais acessível, a Língua Portuguesa poderá ser ensinada como segunda língua, na modalidade escrita.

De acordo com as Diretrizes Curriculares Nacionais (BRASIL, 2001b), as adaptações curriculares são definidas como:

[...] possibilidades educacionais de atuar frente às dificuldades de aprendizagem dos alunos. Pressupõem que se realize a adaptação do currículo regular, quando necessário, para torná-lo apropriado às peculiaridades dos alunos com necessidades especiais. Não um novo currículo, mas um currículo dinâmico, alterável, passível de ampliação, para que atenda realmente a todos os educandos. Nessas circunstâncias, as adaptações curriculares implicam a planificação pedagógica e as ações docentes fundamentadas em critérios que definem o que o aluno deve aprender; como e quando aprender; que formas de organização do ensino são mais eficientes para o processo de aprendizagem; como e quando avaliar o aluno (BRASIL, 2001, p. 33).

Compreendemos, todavia, que a escola tem seu currículo desenvolvido por e para ouvintes; adaptações, no caso de alunos surdos, nem sempre garantem um aprendizado efetivo, considerando que sua primeira língua (Libras) sequer aparece em documentos oficiais como parte de um currículo. Pensando nas propostas de educação bilíngue, como figuram no Decreto 5.626 (BRASIL, 2005), alunos surdos são atendidos, na Educação Infantil e primeira etapa do Ensino Fundamental, em salas de aula cuja língua de instrução é Libras. Assim sendo, acredita-se que tenham um currículo pensado para atender às suas necessidades. Então, pensemos que a questão curricular necessita ao menos ser discutida para as fases seguintes - etapas finais do Ensino Fundamental e Ensino Médio, quando os alunos são incluídos em sala de aula regular com a presença de TILS.

Entende-se também que, embora o Decreto 5.626 determine uma série de adequações no espaço escolar (BRASIL, 2005), esta, possivelmente, não é a realidade da maioria dos municípios de nosso país. Portanto, se mostra relevante refletir e discutir sobre o tipo de material que vem sendo ofertado aos alunos surdos, desde a publicação deste documento, visto que esta pode ser a única forma de atender às necessidades desses alunos.

Antes de adentramos na temática dos materiais pensados e disponibilizados para os alunos surdos é necessário compreender a finalidade de um material didático na educação e aprendizagem de um aluno, e o modo que estes estão dispostos atualmente. De acordo com Bandeira (2009, p. 14), "o material didático pode ser definido amplamente como produtos pedagógicos utilizados na educação e, especificamente, como o material instrucional que 
se elabora com a finalidade didática", ou seja, compreende-se como material didático todo e qualquer material elaborado com a finalidade de ensinar/instruir na aprendizagem.

Para Freitas (2007, p. 21), os materiais didáticos, também conhecidos como recursos e/ou tecnologias educacionais, "são todo e qualquer recurso utilizado em um procedimento de ensino, visando à estimulação do aluno e à sua aproximação do conteúdo". Tendo, portanto, estas definições como base, pode-se dizer que o material é um dos principais meios de ensino e pilares na educação como a figura do professor.

Freitas (2007, p. 27) ressalta ainda que no Brasil "as sucessivas reformas educacionais incluem materiais didáticos inovadores, como exigências de novas filosofias e/ou metodologias de ensino, que agregam aos conceitos didáticos e pedagógicos a reformulação da prática docente". Porém, a persistente predominância dos materiais impressos ainda prevalece nas escolas (ROJO, 2005).

Bandeira (2009) ressalta algumas possíveis hipóteses para o fato de os materiais impressos serem atualmente os mais frequentes nas escolas:

- na educação, o material impresso, tradicionalmente conhecido, sempre foi aceito por alunos, professores e especialistas;

- de fácil manuseio, o material impresso pode ser utilizado em todas as etapas e modalidades da educação, o aluno e o professor podem consulta-lo fora da sala de aula;

- o material impresso não requer equipamento ou recurso tecnológico para sua utilização (BANDEIRA, 2009, p. 16).

Ainda com relação às possíveis hipóteses apresentadas, Freitas (2007, p. 17) faz alguns levantamentos como o fato de que "a produção de materiais e equipamentos didáticos deriva mais dos interesses dos fabricantes e dos fornecedores do que da necessidade dos educadores e educandos". Nesse contexto é possível refletirmos, portanto, sobre as necessidades dos alunos surdos perante os materiais ofertados nas escolas regulares. E, conforme já discutido, acerca da importância de um currículo adaptado, respeitando as necessidades e especificidades de cada aluno, questionamos se tais materiais ofertados têm atendido às demandas desses alunos; e quais materiais vêm sendo disponibilizados. Deve-se considerar que a Língua Portuguesa, para o surdo, é sua segunda língua; possivelmente esse aluno terá dificuldades em acessar um material ou currículo que seja elaborado por ouvintes e para ouvintes em Língua Portuguesa. Nesses casos, a Libras e a visualidade precisam e devem ser consideradas.

Ramos (2013) aponta que, a partir de 2005, com a vigência do Decreto 5.626, e com ações políticas públicas, o uso da Libras em "atividades e nos conteúdos curriculares desenvolvidos em todos os níveis, etapas e modalidades de educação" vem se tornando cada vez mais presente, de tal modo que a elaboração de novas propostas e novos projetos que garantam ao alunado surdo materiais didáticos com acessibilidade na Libras vem se tornando cada vez mais indispensável (RAMOS, 2013, p. 4). 
Como já mencionado, o material tem por principal finalidade ser a "ponte" entre o currículo e o aluno. A escolha pelo uso do currículo adaptado, ou seja, de um currículo pensado e elaborado a fim de atender às demandas do aluno com surdez, é necessária. É preciso inserir nesse currículo questões específicas da surdez - que considerem, por exemplo, a visualidade -, bem como, da cultura surda, que é única e com uma infinidade de particularidades e características. Por sua vez, ao elaborar um material adaptado, mas pensado para aluno surdo, é necessário trazer esse material ao contexto e cultura do aluno surdo, em que a Libras aparece como fator fundamental de desenvolvimento e acessibilidade.

Um exemplo disso é a "Coleção Pitanguá", ${ }^{2}$ organizada pela Editora Moderna, que visa trazer diversos conteúdos de disciplinas da educação básica de um modo inovador. Essa coleção consiste em livros digitais, apresentados em CD-ROM ${ }^{3}$ em Libras e em forma escrita. Esses livros foram distribuídos gratuitamente para as escolas públicas com estudantes surdos. Seguindo esse mesmo modelo há outros materiais como "Trocando ideias: alfabetização e projetos" da editora Scipione, ${ }^{4}$ Coleção Porta Aberta, da Editora FTD.

Um dos materiais disponíveis também, todavia estes em menor escala, são vídeos em Libras; de acordo com Kawase (2015, p. 14), "esse recurso surge na intenção de substituir/ complementar os demais materiais didáticos impressos presentes em sala de aula para o ensino e aprendizagem dos alunos em geral, além de funcionar como alternativa compensatória das perdas dos conteúdos pelos alunos surdos". Um exemplo destes são os vídeos produzidos pelo Instituto Nacional de Educação de Surdos (INES) e disponibilizados gratuitamente, intitulados "Coleção Educação de Surdos - 10 volumes". A autora aponta ainda para iniciativas dos profissionais atuantes nas próprias escolas inclusivas bilíngues, que vêm produzindo vídeos didáticos em Libras para uso próprio e criando um acervo para os futuros alunos surdos que se matricularem.

Destacamos apenas que esses materiais referidos não são adaptados, mas sim pensados e elaborados para o público surdo. Acredita-se que tais materiais, cujo alcance é mais "local", poderiam ser difundidos como iniciativas positivas, a fim de incentivar novas produções e materiais mais adequados à especificidade da surdez.

\section{Delineamento Metodológico}

Considerando os apontamentos prévios - as dificuldades de oferecer acesso igualitário aos conhecimentos, a formação precária de professores, a necessidade de currículo adequado ao aluno surdo, a escassez de material ofertado ao aluno surdo -, este estudo se mostra relevante, pois objetivou analisar, no período após a publicação do Decreto 5.626 (BRASIL, 2005) e por meio de levantamento bibliográfico, que materiais pedagógicos adaptados são ofertados atualmente para os alunos surdos, bem como, os meios e formatos

\footnotetext{
http://www.moderna.com.br/pnld2013/PITANGUAciencias/

COMPACT DISC - Read-Only-Memory.

http://editora-arara-azul.com.br/site/projetos/detalhes/13
}

Comunicações $\mid$ Piracicaba $\mid$ v. $25 \mid$ n. $3 \mid$ p. 293-320 $\mid$ set-dez. 2018 
de mídias em que esses materiais são ofertados, a fim de auxiliar o processo de ensino e aprendizagem desses alunos.

A opção pelo período indicado - a partir do ano de 2005, ano da publicação do referido Decreto até 2017 - se deve à hipótese de que tenham ocorrido novas experiências e propostas educacionais que considerem esse aluno surdo em sala de aula, como materiais, avaliações, metodologias de ensino que favoreçam sua real inclusão escolar.

Como objetivos específicos, pretendeu-se verificar o que foi difundido após a publicação do Decreto e se, na literatura científica encontrada, é possível identificar alguma alteração na prática escolar; e também investigar se foram realizadas adaptações em currículos e materiais pedagógicos para alunos surdos, bem como as propostas dos mesmos.

A metodologia utilizada neste estudo consistiu em uma revisão bibliográfica de natureza exploratória. Esta permite realizar o levantamento dos aspectos teóricos e metodológicos necessários ao alcance dos objetivos estabelecidos.

No que se refere à natureza exploratória, Gil (2002) destaca que o objetivo desse modelo é "proporcionar maior familiaridade com o problema, com vista a torná-lo mais explícito ou a construir hipóteses". E complementa que "estas pesquisas têm como objetivo principal o aprimoramento de ideias ou a descoberta de intuições. Seu planejamento é, portanto, bastante flexível, de modo que possibilite a consideração dos mais variados aspectos relativos ao fato estudado" (GIL 2002, p. 41).

Dessa forma, para atender aos objetivos da pesquisa, realizou-se um levantamento bibliográfico por meio de buscas em bases de dados nacionais. Foram selecionadas as seguintes bases: Scielo Brasil, uma base de dados científicos eletrônica e Portal de periódicos CAPES. A escolha de tais bases se deveu ao fato de se tratar de fontes científicas fidedignas e atualizadas, que podem fornecer informações confiáveis, bem como, favorecer maior abrangência do tema pesquisado.

Os descritores para a busca nas bases de dados brasileiras foram: Adaptação surdez, Currículo surdez, Currículo Adaptado Surdez, Material Didático Surdez, Material Didático Libras, Adaptação Libras, Currículo Libras, Currículo Adaptado Libras, Tecnologia Libras, Tecnologia Surdez e, por fim, Ensino Surdez. As palavras poderiam estar em qualquer campo do registro, tais como título, resumo e/ou palavras-chave.

No total, foram encontrados 1.905 registros de artigos em uma busca inicial; destes, 1.827 foram encontrados no Portal de Periódicos da CAPES, e 78 no Portal de Periódicos Scielo. Após uma filtragem por data, foram obtidos 1.220 no Portal de Periódicos da CAPES e 68 no Portal de Periódicos Scielo. Tal requisito foi escolhido como filtro, uma vez que um dos objetivos da pesquisa é investigar as possíveis mudanças ocorridas após a lei do Decreto 5.626 entrar em vigor.

Posteriormente, adotou-se como critério de seleção a língua em que o registro se encontrava, o qual correspondia à Língua Portuguesa. Foram encontrados, portanto, 549 registros no Portal de Periódicos da CAPES e 66 no Portal de Periódicos Scielo.

Outro filtro utilizado na pesquisa correspondia ao formato em que o registro foi publicado, considerando apenas registros em artigos e dissertações, sendo desconsideradas publi- 
cações em revistas, anais, publicações de livros, atas e congressos entre outros formatos. Tal escolha se deu em função da viabilização do desenvolvimento do estudo no período proposto, para a sua realização como um trabalho de conclusão de curso. Foram encontrados, portanto, 418 registros no Portal de Periódicos da CAPES e 61 no Portal de Periódicos Scielo.

Após a filtragem dos requisitos citados, foram analisados todos os títulos dos registros encontrados, a fim de averiguar quais atendiam ao tema e objetivos da pesquisa, restando, assim, 82 registros no Portal de Periódicos da CAPES e 18 no Portal de Periódicos Scielo.

Por fim, a partir de todas as filtragens, foi realizada a leitura dos resumos dos artigos e teses selecionados, restando, assim, 11 registros, sendo 8 no Portal de Periódicos da CAPES e, apenas, 3 no Portal de Periódicos Scielo.

Mostramos, a seguir, os dados de forma quantitativa (com relação às pesquisas encontradas), a título de conhecimento da produção científica atualizada sobre a temática proposta, e possíveis causas e desdobramentos desse quantitativo. Posteriormente, exibimos os conteúdos presentes nas publicações encontradas, com a finalidade de analisar que materiais pedagógicos (e de que tipos e formatos) vêm sendo ofertados ao alunado surdo nos últimos doze anos. As análises foram desenvolvidas com fundamentação na legislação vigente e em autores da área da surdez como: Lacerda, Santos e Caetano (2013), o próprio Decreto 5.626 (BRASIL, 2005), e Nogueira e Cabello (2017).

\section{Resultados E Discussão}

Foram encontrados inicialmente 1.905 registros, restando para a análise final apenas 11 registros. Dos 11 descritores utilizados na pesquisa, apenas cinco apresentaram resultados finais relevantes, sendo que destes apenas um descritor obteve resultado no portal de periódico Scielo, como demonstra o gráfico a seguir:

Figura 1: Resultado final por descritor.

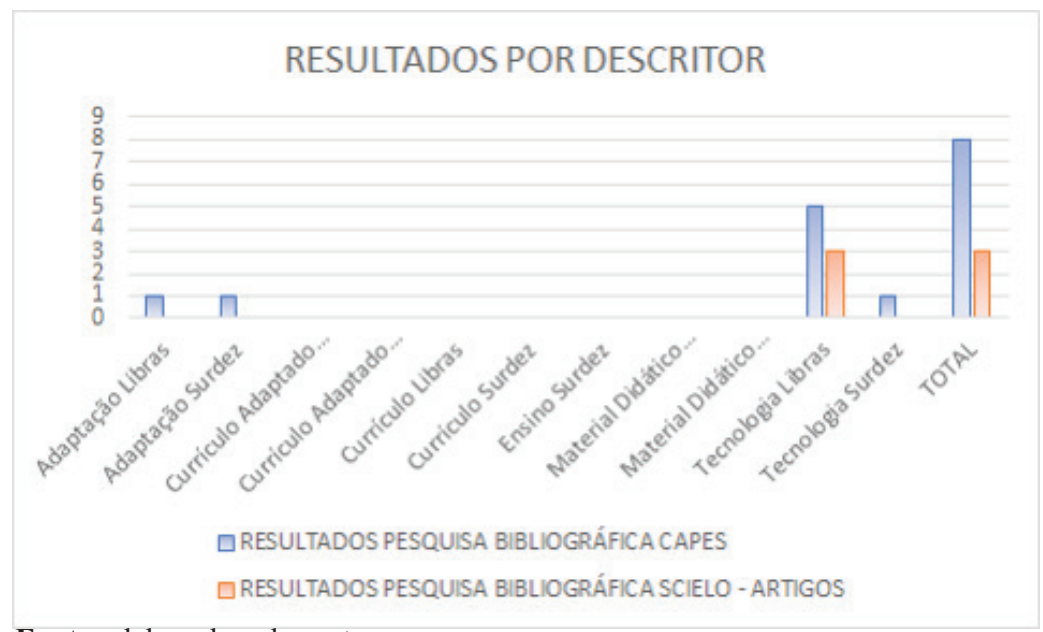

Fonte: elaborado pelas autoras. 
O descritor mais significativo em termos de resultados para a análise foi "Tecnologia Libras", tendo cinco registros finais no Portal de Periódicos da CAPES e três registros finais no Portal de Periódicos Scielo, como aponta o gráfico a seguir. Pressupõe-se que tal resultado deriva do crescimento de publicações sobre o uso de tecnologias de informação e comunicação (TIC) no ambiente educacional.

Figura 2: Gráfico Tecnologia Libras.

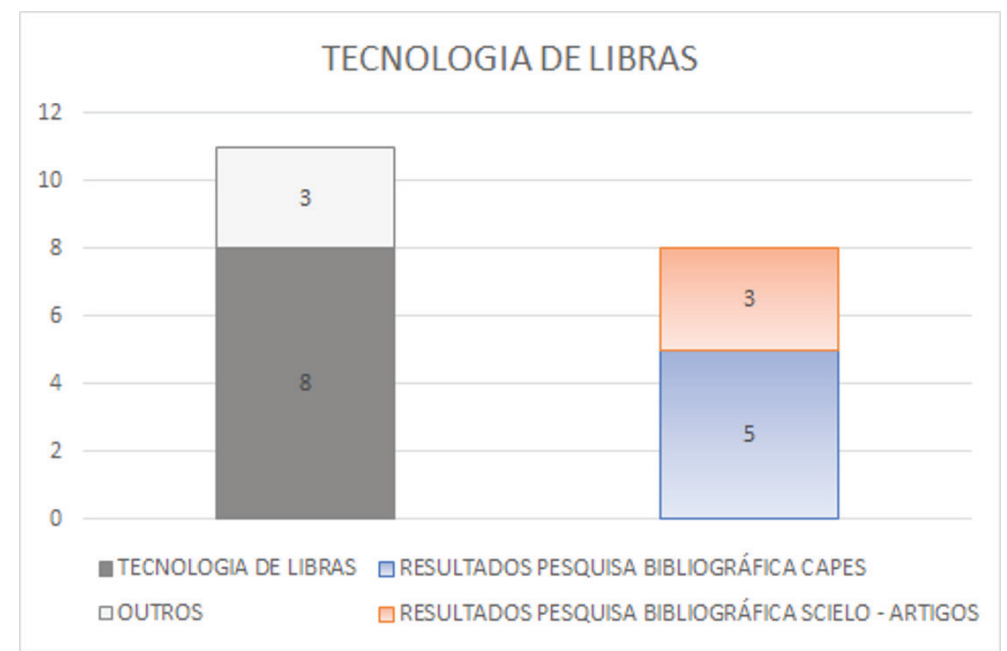

Fonte: elaborado pelas autoras.

$\mathrm{O} \operatorname{MEC}(\mathrm{s} / \mathrm{d}$.) aponta que durante o processo de incorporação das tecnologias no ambiente educacional:

[...] aprende-se a lidar com a diversidade, a abrangência e a rapidez de acesso às informações, bem como com novas possibilidades de comunicação e interação, o que propicia novas formas de aprender, ensinar e produzir conhecimento, que se sabe incompleto, provisório e complexo (MEC, s/d, p. 61).

É evidente, na atualidade, que a tecnologia se encontra na "palma das mãos", e de certo modo, com um acesso muito fácil e rápido. Esse fato contribui, portanto, para que os acessos aos conteúdos escolares sejam igualmente mais rápidos, fáceis e mais eficazes que os materiais tradicionais.

Sendo assim, ao associar a palavra Tecnologia a Libras, compreende-se que o fato da Libras ser uma língua visuogestual, sua aprendizagem torna-se muito mais eficaz quando apresentada de modo visual, por meio de vídeos e/ou outros recursos que explorem essa característica da língua. Considerando que na educação de surdos (e na educação geral) o material cedido pelas escolas muitas vezes possui caráter impresso, tal tecnologia visa mediar e facilitar o processo de ensino-aprendizagem. 
Um descritor a ser analisado também com criticidade são os referentes ao currículo adaptado ("Currículo Adaptado Surdez" e "Currículo Adaptado Libras"), que podem ser observados no gráfico a seguir. Obteve-se, inicialmente, apenas 19 registros no total, sendo oito registros para "Currículo Adaptado Surdez" e 11 registros para "Currículo Adaptado Libras" no Portal de Periódicos da CAPES, e nenhum registro tanto para "Currículo Adaptado Surdez" como para "Currículo Adaptado Libras" no Portal de Periódicos Scielo. Considerando que os registros datavam a partir de 2006 no descritor "Currículo Adaptado Libras" e a partir de 2010 no descritor "Currículo Adaptado Surdez".

Figura 3: Gráfico Currículo Adaptado Libras e Currículo Adaptado Surdez.

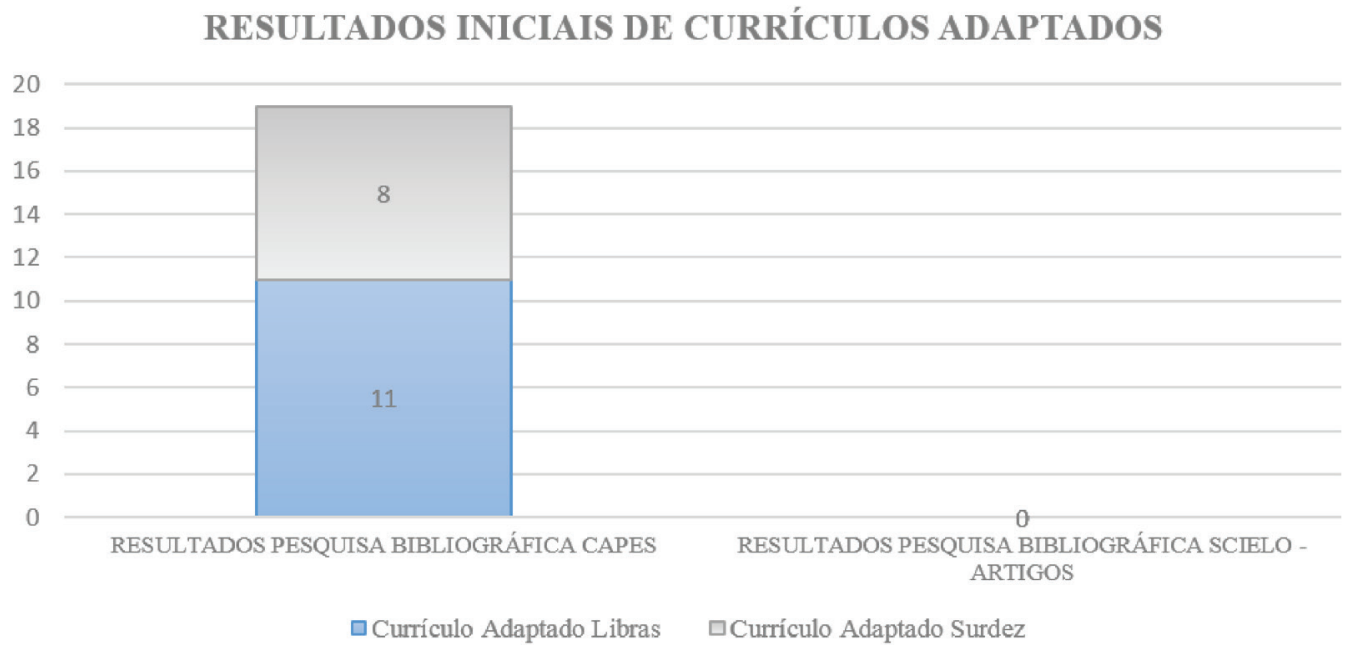

Fonte: elaborado pelas autoras.

De acordo com o MEC/SEESP/SEB (2003, p. 22), adaptações curriculares são estratégias e critérios de situação docente, admitindo decisões que "oportunizam adequar a ação educativa escolar às maneiras peculiares de aprendizagem dos alunos, considerando que 0 processo de ensino-aprendizagem pressupõe atender à diversificação de necessidades dos alunos na escola". Mediante tal citação e os números de resultados obtidos, é possível questionarmos se tal temática vem sendo discutida de maneira efetiva. Quando uma escola dita inclusiva recebe alunos surdos se espera que algumas mudanças mínimas sejam efetuadas com o intuito de atender adequadamente a tal alunado. O número reduzido de publicações sobre adaptação curricular nos leva a uma reflexão a respeito do que os professores têm modificado em suas aulas para atender a tais alunos.

Assim como na definição já trazida por Franco (2007), os termos acomodar e adequar são sinônimos da palavra adaptação. Todavia, ao usá-las no ensino de alunos surdos, é necessário olharmos para tais terminologias de modo mais cuidadoso. Embora o Decreto 5.626 (BRASIL, 2005) aponte para a necessidade de uma educação bilíngue para surdos (envolvendo a presença de diversos profissionais e o respeito pela diversidade linguística), 
há também que se considerar a mudança de metodologia de ensino por parte do professor regente, por exemplo. Lacerda et al. (2013) abordam a relevância da reflexão acerca da apresentação dos conteúdos quando se tem alunos surdos incluídos em sala de aula. As autoras indicam a necessidade de uso de elementos visuais/imagéticos para a construção de sentidos e conceitos, e trazem o conceito de Pedagogia Visual como fundamental para a compreensão de como se dá o aprendizado pelo aluno.

Questionamos, assim, se acomodar ou adaptar materiais é o suficiente para promover a aprendizagem. Parece-nos que não basta realizar pequenas alterações no currículo para atender às especificidades do alunado surdo, mas é necessário pensar um currículo outro, elaborado a partir de um olhar que considere que os conceitos são apropriados pela visualidade.

\section{AnÁlise dos Registros encontrados}

Nesta seção, analisaremos mais especificamente os registros encontrados e, para tal, selecionamos, inicialmente, por eixos a partir dos descritores. Sendo assim, de acordo com o descritor "Tecnologia Libras" obtivemos os seguintes registros:

Tabela 1: Registros Finais - Tecnologia Libras.

\begin{tabular}{|c|c|c|c|c|}
\hline PORTAL & TÍTULO & AUTOR & ANO & $\begin{array}{l}\text { TIPO DE } \\
\text { ARQUIVO }\end{array}$ \\
\hline \multirow[t]{3}{*}{ SCIELO } & $\begin{array}{l}\text { Aplicação de um Programa de Ensino de } \\
\text { Palavras em Libras Utilizando Tecnologia } \\
\text { de Realidade Aumentada }\end{array}$ & $\begin{array}{l}\text { Dariel de Carvalho e } \\
\text { Eduardo José Manzini }\end{array}$ & 2017 & Artigo \\
\hline & $\begin{array}{c}\text { Características de repositório educacional } \\
\text { aberto para usuários de língua brasileira } \\
\text { de sinais }\end{array}$ & $\begin{array}{c}\text { Romario Antunes da Silva } \\
\text { e Rosângela Schwarz } \\
\text { Rodrigues }\end{array}$ & 2013 & Artigo \\
\hline & $\begin{array}{l}\text { Libras no ensino de inglês mediado } \\
\text { pelas novas tecnologias: desafios e } \\
\text { possibilidades }\end{array}$ & $\begin{array}{c}\text { Kátia Cristina do Amaral } \\
\text { Tavares e Ana Paula Pires de } \\
\text { Oliveira }\end{array}$ & 2014 & Artigo \\
\hline \multirow[t]{5}{*}{ CAPES } & $\begin{array}{l}\text { Aprendizagem lúdica como suporte à } \\
\text { educação de crianças surdas por meio de } \\
\text { ambientes interativos }\end{array}$ & $\begin{array}{l}\text { Juliano Soares dos Santos e } \\
\text { Francisco Antônio Pereira } \\
\text { Fialho }\end{array}$ & 2012 & Tese \\
\hline & $\begin{array}{l}\text { Avaliação dos docentes e futuros } \\
\text { docentes, quanto ao conhecimento e } \\
\text { utilização de mídias interativas nas } \\
\text { práticas pedagógicas }\end{array}$ & $\begin{array}{c}\text { Danielle Marie Macedo } \\
\text { Sousa e Isabel Virgolino } \\
\text { Egídio }\end{array}$ & 2016 & Artigo \\
\hline & $\begin{array}{c}\text { Customizando Ambientes na Web para } \\
\text { Língua Brasileira de Sinais Usando Web- } \\
\text { Services }\end{array}$ & $\begin{array}{c}\text { Vinícius Costa Souza; Sérgio } \\
\text { Crespo Pinto }\end{array}$ & 2009 & Artigo \\
\hline & $\begin{array}{l}\text { Projeto de pesquisa: software glossário } \\
\text { de informática com aplicação de libras e } \\
\text { de tecnologia de captura de movimento } 3 \mathrm{~d}\end{array}$ & $\begin{array}{l}\text { Sonia Maria Dechandt } \\
\text { Brochado, Cristina Broglia } \\
\text { De Feitosa Lacerda e Luiz } \\
\text { Renato Martins da Rocha }\end{array}$ & 2016 & Artigo \\
\hline & $\begin{array}{c}\text { Sistema de Tecnologia Assistiva para } \\
\text { captar a atenção de deficientes auditivos } \\
\text { e surdos }\end{array}$ & Marcelo Sodré Plachevski & 2014 & Tese \\
\hline
\end{tabular}

Fonte: elaborado pelas autoras. 
O texto intitulado "Aplicação de um Programa de Ensino de Palavras em Libras Utilizando Tecnologia de Realidade Aumentada" propõe a aplicação de um software para o ensino de palavras do português por meio da Libras. Os autores realizaram uma avaliação inicial do conhecimento de vocábulos por sujeitos surdos, uma intervenção com o software, e uma segunda avaliação, visando coletar informações sobre erros e acertos com relação à apreensão de palavras do português. Por fim, afirmam que a partir dos resultados podem-se repensar os processos de ensino e escrita do aluno com surdez.

Compreendemos que os autores apresentam uma ferramenta tecnológica como recurso fundamental para o ensino do português para o aluno surdo. O texto não aponta para a necessidade de quaisquer adaptações por parte de professores ou alterações de metodologia de ensino; a tecnologia aparece como única ferramenta de ensino, podendo ser aplicada para a ampliação de vocabulário em português. Não é possível, pelo contexto apresentado, identificar de que forma o ensino de palavras por um software pode colaborar efetivamente para a educação de surdos, visto que não se propõe nada especificamente para o público surdo - apenas se indica que o recurso permite a ampliação de vocabulário.

Já com relação ao estudo "Libras no ensino de inglês mediado pelas novas tecnologias: desafios e possibilidades", as autoras se propõem a investigar a perspectiva dos diferentes sujeitos na escola, com relação aos desafios do ensino de inglês para surdos. Por meio de entrevistas, questionários e grupo focal, um dos temas que emergiram nas análises foi a mediação da tecnologia nas aulas de inglês. Todavia, nos resultados é possível destacar que a tecnologia resumiu-se à apresentação de vídeos da internet e uso do computador como ferramenta de comunicação (via Língua Portuguesa, texto escrito), o que, muitas vezes, acabou por atrapalhar a aula, devido às limitações tecnológicas da escola.

Concordamos com as afirmações de Nogueira e Cabello (2017, p. 245); é preciso refletir sobre como tais "adaptações" podem de fato favorecer a educação de surdos:

Trabalhos publicados na primeira década dos anos 2000, que já relacionavam a
temática da tecnologia e da surdez, tal como citado por Nogueira (2014) mesmo
que já não pudessem ser alocados em uma perspectiva assistiva da tecnologia,
ainda assim não dialogam diretamente com o modo como buscamos compreen-
der as relações entre o aluno surdo, as tecnologias e a escola. Embora defendes-
sem as tecnologias de informação e comunicação (TICs) como espaço possível
para a participação social e o acesso à informação pelas pessoas surdas, con-
forme Nogueira (2014) destaca, esses estudos ainda não focalizavam os modos
pelos quais as TICs poderiam ser efetivamente empregadas em contextos de
ensino de alunos surdos (grifos das autoras.

Ressaltando a importância do uso das tecnologias no ensino aprendizagem de pessoas surdas, o estudo "Características de repositório educacional aberto para usuários de língua brasileira de sinais" baseou-se em uma pesquisa exploratória, realizada com os alunos surdos e ouvintes do curso Letras-Libras na modalidade a distância da Universidade Federal de Santa Catarina. Teve por intuito averiguar as características que um repositório educacional aberto deve apresentar para atender às necessidades de informação dos alunos 
surdos e ouvintes. Nas considerações finais, os autores apontam que o uso da internet, não somente nas atividades acadêmicas como também em casa e no ambiente de trabalho, é de fundamental importância, principalmente se tratando das ferramentas que a própria internet disponibiliza, como: e-mails, o Messenger, ferramenta de compartilhamento de vídeo, como o YouTube e sites para surdos.

O texto ressalta ainda que "os suportes requisitados para acesso à informação são os dicionários, vídeos, livros digitais e artigos. Os alunos preferem acessar as informações no repositório por meio de língua de sinais, legendas e em português" (SILVA; RODRIGUES, 2013, p. 1). Tal resultado provoca a reflexão sobre a importância da acessibilidade e maior facilidade de uso do ambiente/meio virtual. Embora os materiais utilizados como suporte não sejam inovadores, a pesquisa aponta para a acessibilidade aos mesmos, via Libras, como fundamental.

Nesse contexto, o artigo "Customizando Ambientes na Web para Língua Brasileira de Sinais Usando Web-Services" nos traz uma possível solução para o uso da internet por esse público; o texto aborda o uso de uma biblioteca que fornece os recursos necessários para que softwares ancorados na web possam utilizar a Língua Brasileira de Sinais. Esse sistema se baseia no SignWriting ${ }^{5}$, um sistema de representação gráfica das línguas de sinais que permite, por meio de símbolos visuais representar as configurações das mãos, seus movimentos, as expressões faciais e os deslocamentos corporais. O estudo aborda a utilização do sistema, bem como, quais softwares da web fazem uso desse recurso. Para a efetuação deste estudo, foi realizado um estudo de caso, o qual objetivou testar o Web-Services, ${ }^{6}$ desenvolvido por meio de um fórum de discussão. Constatou-se que a comunidade de desenvolvedores tem à disposição os recursos necessários para disponibilizar a escrita em Libras, por intermédio do uso da biblioteca SWService. Cabe, portanto, refletir se o uso do SignWriting tem ampla divulgação entre as comunidades surdas e se seria uma opção viável para a educação de surdos - considerando se tratar de mais uma forma de escrita, além do português.

Ainda nessa perspectiva de softwares, o trabalho intitulado "Projeto de pesquisa: software glossário de informática com aplicação de libras e de tecnologia de captura de movimento 3D" tem por objetivo o desenvolvimento de produtos, serviços e metodologias de tecnologia assistiva, voltados ao multiletramento de pessoas surdas. Para isso, o estudo conta com "o uso de tecnologia de captura de movimento, empregando bases de dados de movimentação facial e corporal, associada à comunicação oral e em Libras, que serão utilizadas e incorporadas a avatares 2D e 3D" (BROCHADO; LACERDA, 2016, p. 906.) Devido ao projeto de desenvolvimento dos softwares ainda estar em andamento no presente momento da pesquisa, as considerações trazidas pelos autores se baseiam em resultados parciais, todavia com indicações positivas em relação ao software, destacando o fato de que a produção deste contribuirá para a acessibilidade e inclusão, pois busca aproximar pessoas

5 Desenvolvido por Valerie Sutton e difundido pelo Deaf Action Committee for SignWriting - DAC em La Jolla na Califórnia.

6 São componentes de software que independem de implementação ou de plataforma e podem ser descritos, publicados e invocados sobre uma rede, geralmente a Web, por meio de mensagens padrão XML [PIN 2002]. 
surdas e ouvintes. Acreditamos que tais resultados podem contribuir para a educação, pois por meio do software se possibilita que surdos e ouvintes tenham acesso ao mesmo conteúdo, bem como, a maior interação entre aluno-professor, sendo que o último, mesmo não tendo conhecimento de Libras, será capaz de compreender e até mesmo se aproximar do aprendizado da língua.

Porém, todo e qualquer recurso, adaptação e/ou material hoje disponibilizados necessitam de uma prática que torne sua utilização mais eficaz no processo de ensino aprendizagem. Para tal questionamento, o estudo "Avaliação dos docentes e futuros docentes, quanto ao conhecimento e utilização de mídias interativas nas práticas pedagógicas" visa analisar o quanto os docentes - que lecionam em uma Escola Estadual de Ensino Fundamental, e futuros docentes, alunos das Licenciaturas da Educação à Distância (ambos no Estado de Paraíba) - dominam e utilizam os recursos midiáticos em suas aulas, e o que os alunos da educação a distância acham da utilização dos recursos midiáticos nas Práticas Pedagógicas.

Os autores destacam a dificuldade encontrada pelos docentes que já atuam na área em utilizar tais recursos, devido à falta de domínio no manuseio de tais recursos. E apontam que "Não adianta impor o uso de computadores, meios impressos, DVDs entre outros, se o profissional não está apto a lidar com essas novas tecnologias" (SOUSA; EGÍDIO, 2016, p. 67). Em contrapartida, os futuros docentes apresentaram domínio e total motivação na utilização desses recursos. Os autores destacam a necessidade de professores que busquem novas perspectivas, mudanças em suas técnicas educacionais e de planejamento. Contudo, vale ressaltar, novamente, que o contexto exibido se refere ao Ensino Superior, e não à educação básica.

Já o estudo "Aprendizagem lúdica como suporte à educação de crianças surdas por meio de ambientes interativos" aponta uma abordagem que corresponde à perspectiva necessária trazida por Souza e Egídio (2016). E apresenta como objetivo de pesquisa desenvolver um modelo de suporte à educação, ancorado em ambientes interativos lúdicos, que facilitem o aprendizado da Libras como primeira língua para crianças surdas. Os autores salientam que a particularidade deste trabalho foi utilizar o processo de desenvolvimento de um software. Nota-se mais uma vez a presença de novas tecnologias no ambiente educacional, promovendo novas práticas de ensino e aprendizagem. Os autores acentuam que a "aquisição da linguagem não é meramente um caso de passivo de transferência de informação para a criança. É um processo onde elas constroem ativamente sua língua". O procedimento da pesquisa constou na aplicação da pirâmide metodológica de Brathwaite e Schreiber $(2008)^{7}$ junto a quatro turmas do ensino fundamental de duas escolas públicas da grande Florianópolis. E destaca em seus resultados que os objetivos propostos pela pesquisa foram atingidos.

É valido ressaltar, portanto, que a utilização de ambientes interativos e lúdicos influencia e colabora no ensino aprendizagem de alunos surdos, assim como é importante saber executar e dominar os recursos que as novas tecnologias nos oferecem atualmente, a fim de ofertar o ensino de maior qualidade.

BRATHWAITE, Brenda; SCHREIBER, Ian. Challenges for game designers. Boston: Charles River Media, 2008. 
E, por fim, Plachevski (2014) em seu trabalho "Sistema de Tecnologia Assistiva para captar a atenção de deficientes auditivos e surdos" nos mostra que, "o ato ou gesto para captar a atenção do Deficiente Auditivo, DA, para iniciar a comunicação é atualmente uma barreira no processo, sendo necessário ter uma comunicação visual direta e até mesmo aproximação e contato físico para captar a atenção do deficiente auditivo" (PLACHEVSKI, M. 2014, p. 8). E, dessa forma, teve por objetivo criar um dispositivo que utiliza o conceito de tecnologia assistiva:

\begin{abstract}
Recentemente foi inserida na cultura educacional brasileira, a terminologia tecnologias assistivas, apresentando-se paralelamente à expressão ajudas técnicas, no que diz respeito aos recursos que favorecem a funcionalidade e aos serviços que têm por objetivo promover a avaliação, indicação, confecção e orientação para o desenvolvimento de autonomia funcional do usuário da tecnologia assistiva (ALVES, 2006, p. 18).
\end{abstract}

Portanto, tecnologia assistiva é "uma expressão utilizada para identificar todo o arsenal de recursos e serviços que contribuem para proporcionar ou ampliar habilidades funcionais de pessoas com deficiência e, por conseguinte, promover vida independente e inclusão" (ALVES, 2006).

Plachevski (2014) complementa em seu estudo que esse dispositivo usa a tecnologia de reconhecimento de voz em um dispositivo móvel, independente do locutor e de palavras isoladas, que é capaz de gerar um alerta vibratório para o deficiente auditivo. E comprova que o disposto obteve eficácia em seu uso, o qual conta com palavras utilizadas atualmente para se iniciar um diálogo, essas palavras são previamente registradas na memória do dispositivo. $\mathrm{O}$ estudo em si não traz apontamentos para a educação, mas se crê que esse estudo é relevante para o meio educacional, pois tendo esse dispositivo em sala de aula, a interação professor-aluno, ou intérprete-aluno se torna mais eficaz, uma vez que ambos os profissionais conseguem de certa forma prender a atenção do aluno no conteúdo que está sendo ensinado. Motivo pelo qual este estudo não foi excluído da presente pesquisa.

Com bases em todos esses estudos citados, é possível ter uma breve conclusão da importância da utilização das novas tecnologias, não só no ambiente educacional, como também nos diversos ambientes de que a pessoa surda faz parte. Porém, é necessário destacar que a maioria dos textos se refere à tecnologia como softwares, vídeos, canais da internet, e tentativas de aproximação desses meios com a Libras. Nenhum dos textos faz menção a materiais didáticos específicos, criados para alunos surdos (em quaisquer etapas educacionais) ou pensados de forma a priorizar a visualidade.

Por fim, serão apresentados os descritores que obtiveram apenas um resultado para cada; estes correspondem à "Adaptação Surdez", "Adaptação Libras" e "Tecnologia Surdez", todos no Portal de periódico da CAPES. Como mostra a tabela a seguir. 
Tabela 2: Registros Finais - "Adaptação Surdez", "Adaptação Libras" e "Tecnologia Surdez"

\begin{tabular}{|c|c|c|c|c|c|}
\hline PORTAL & DESCRITOR & TÍTULO & AUTOR & ANO & $\begin{array}{c}\text { TIPO DE } \\
\text { ARQUIVO }\end{array}$ \\
\hline \multirow[t]{3}{*}{ CAPES } & Adaptação Surdez & $\begin{array}{l}\text { A escola inclusiva } \\
\text { e estratégias para } \\
\text { fazer frente a ela: as } \\
\text { adaptações curriculares }\end{array}$ & $\begin{array}{c}\text { Eladio Sebastian } \\
\text { Heredero }\end{array}$ & 2010 & Artigo \\
\hline & Adaptação Libras & $\begin{array}{c}\text { Proposição de Recursos } \\
\text { Pedagógicos Acessíveis: } \\
\text { O Ensino de Química e a } \\
\text { Tabela Periódica }\end{array}$ & $\begin{array}{l}\text { Amélia Rota } \\
\text { Borges Bastos }\end{array}$ & 2016 & Artigo \\
\hline & Tecnologia Surdez & $\begin{array}{l}\text { Livro digital bilíngue } \\
\text { para crianças surdas: } \\
\text { uma análise na } \\
\text { perspectiva do design } \\
\text { visual de interface em } \\
\text { tela }\end{array}$ & $\begin{array}{c}\text { Camila Wohlmuth } \\
\text { da Silva, Jorge } \\
\text { Teixeira Deglaucy, } \\
\text { Vilson João } \\
\text { Batista, Berenice } \\
\text { Santos Gonçalves e } \\
\text { Ricardo Triska. }\end{array}$ & 2014 & Artigo \\
\hline
\end{tabular}

Fonte: elaborado pelas autoras.

Outro estudo que aborda sobre recursos a fim de complementar o ensino é "Proposição de Recursos Pedagógicos Acessíveis: O Ensino de Química e a Tabela Periódica”, que tem por intuito discutir os procedimentos a serem adotados e os cuidados necessários na construção e adequação de recursos pedagógicos para o ensino de alunos com deficiência. E disponibiliza como recurso uma tabela periódica construída a partir dos princípios do desenho universal da aprendizagem, o qual destaca os autores:

\footnotetext{
Dentre os recursos de acessibilidade utilizados para tanto estão: a ampliação da tabela para alunos com baixa visão; a disponibilização de todas as informações escritas no sistema Braille; a construção de verbetes químicos para apoiar a compreensão dos alunos surdos sobre os elementos químicos, uma vez que apenas seis elementos estão dicionarizados na Língua Brasileira de Sinais; a construção de caixas de referência com representações das aplicações dos elementos em objetos, materiais e alimentos do cotidiano, como forma de facilitar a compreensão do tema para alunos com déficit intelectual, dentre outras proposições (BASTOS, 2016).
}

Tais adaptações realizadas são caracterizadas como forma alternativa ao ensino da tabela periódica, segundo a autora, que visa ter o aluno como centro do processo educativo. Ressaltando o fato de que as adaptações são meios de complementar o ensino, não sendo estas o único material e/ou recurso a ser utilizado e disponibilizado. Sabe-se que a criação de sinalários em Libras é fundamental para ampliar a divulgação da mesma e para o acesso ao conteúdo escolar; todavia, "ainda são relativamente poucas as iniciativas de elaboração de repertórios para áreas de especialidades" (OLIVEIRA; STUMPF, 2013, p. 221). Assim sendo o estudo se mostra relevante para a área da educação de surdos. 
Nesse contexto, Heredero (2010) aponta em seu estudo "A escola inclusiva e estratégias para fazer frente a ela: as adaptações curriculares" que "o fundo da questão a analisar não está no próprio instrumento, que sempre foi avaliado como recurso com altas potencialidades, porém, muitas vezes, mal estruturado" (HEREDERO, 2010, p. 193). Seu estudo tem por objetivo analisar quais são os modelos desenvolvidos de inclusão nas escolas brasileiras atualmente e quais as adaptações curriculares são utilizadas como estratégia compatível com modelos inclusivos. Visando trazer diante da comunidade científica a necessidade do entendimento de um instrumento adaptativo, com estratégias e recursos, que permitam ao professor programar objetivos e conteúdo voltados para os alunos com deficiência. Todavia este estudo se caracteriza apenas como um texto formativo, pois não apresenta qualquer recurso propriamente, e sim informações a fim de propiciar meios e estratégias para o planejamento e elaboração dos recursos e estratégias.

Por fim, o artigo intitulado "Livro digital bilíngue para crianças surdas: uma análise na perspectiva do design visual de interface em tela" aborda uma temática extremamente importante para a educação inclusiva brasileira atual, referente ao material ofertado atualmente para alunos surdos. Neste estudo, os autores relatam a importância dos critérios, qualidade e eficiência dos livros digitais. O objetivo da pesquisa se pautou em, por meio de dois eBooks, mostrar critérios e princípios de design visual de interface, especificamente o design de tela, que poderão contribuir para a produção de livros digitais com mais qualidade.

De acordo com os autores, "no contexto brasileiro, há uma carência de material educativo acessível que seja em Língua Brasileira de Sinais e português para contribuir ao processo de aprendizagem em sala de aula" (WOHLMUTH et al., 2014, p. 37) e traz como considerações finais que:

[...] enquanto a criança surda não puder se apropriar adequadamente da cultura surda, da cultura ouvinte e dos meios tecnológicos que estão criando inúmeras alternativas de aplicativos voltados à educação, ou seja, não só exercer plenamente seus direitos de cidadãos, mas poder circular livremente por todas as instâncias sociais, elas continuarão a ser tuteladas por alguém ou por alguma instituição.

Conclui-se, portanto, que a educação inclusiva vigente no Brasil se encontra despreparada para atender às demandas que o aluno com deficiência apresenta, principalmente tratando-se do aluno surdo. Como também a falta de preparo dos profissionais mediante os poucos materiais ofertados, sendo que estes, em sua grande maioria, apresentam caráter digital, como apontam os dados deste estudo.

\section{CONSIDERAÇõES FINAIS}

Encerramos este estudo trazendo as considerações finais e sugestões para futuras pesquisas. Primeiramente, é válido ressaltar que os objetivos da presente pesquisa consistiam 
em averiguar o que foi difundido após a publicação do Decreto 5.626 e se, de acordo com os resultados encontrados na literatura científica foi possível notar alguma alteração na prática escolar, investigar se estão sendo realizadas adaptações em currículos e materiais pedagógicos para alunos surdos, bem como, a proposta dos mesmos.

Destaca-se que pouquíssimos foram os registros finais analisados, em comparação com a busca inicial realizada. Compreende-se que muito se tem falado sobre questões como a inclusão, educação inclusiva, materiais e/ou recursos adaptados, todavia, quando relacionados à temática surdez, tais registros se tornam bastante escassos.

Outro ponto a ser ressaltado se deve ao fato de que, apesar de o descritor "Tecnologia Libras" ter apresentado o maior índice de resultados finais, poucas são as pesquisas que trazem aplicações e/ ou utilização em ambiente educacional de maneira eficaz, como também pouquíssimos são os conhecimentos dos professores frente às novidades tecnológicas.

Este estudo torna evidente que as ideias e objetivos trazidos nos registros encontrados são pertinentes e necessários para o meio educacional. No entanto, a falta de conhecimento necessário acerca da cultura surda, da Libras, e de maneiras de utilizar tais recursos em sala de aula, faz destas ideias e objetivos apenas teoria.

Como mencionado no início da pesquisa, há alguns materiais de conhecimento das autoras como o "Projeto Pitanguá", por exemplo, que sequer foram mencionados nos registros relacionados. Também é possível evidenciar que os meios mais difundidos e discutidos atualmente são os softwares; este fato demonstra que pesquisas atuais não têm feito uso de materiais de qualidade já disponibilizados para melhorar a oferta destes.

E por fim, salienta-se que, com a vigência do Decreto 5.626, a Libras passou a ter maior destaque e importância nas adaptações realizadas, bem como, na produção de softwares que atendam a alunos com necessidades educacionais. No entanto, ressaltamos que apensas inserir a Libras como forma de "adaptação" de materiais pode ser um erro, visto que esta, obrigatoriamente, deve ser o principal recurso de acessibilidade.

\section{REFERÊNCIAS}

ALVES, D. O. Sala de recursos multifuncionais: espaços para atendimento educacional especializado / elaboração Denise de Oliveira Alves, Marlene de Oliveira Gotti, Claudia Maffini Griboski, Claudia Pereira Dutra - Brasília: Ministério da Educação, Secretaria de Educação Especial, 2006.

BANDEIRA, D. Material didático: conceito, classificação geral e aspectos da elaboração. In: . Materiais didáticos. Curitiba, PR: IESDE, 2009, p. 13-34.

BASTOS, A. R. B. Proposição de Recursos Pedagógicos Acessíveis: O Ensino de Química e a Tabela Periódica. Journal of Research in Special Education Needs, v. 16, n. s1. 923927, 2016. 
BRASIL. Declaração de Salamanca e linhas de ação sobre necessidades educativas especiais. Brasília: CORDE, 1994.

. Secretaria de Educação Fundamental. Parâmetros curriculares nacionais: introdução aos parâmetros curriculares nacionais / Secretaria de Educação Fundamental. Brasília: MEC/SEF, 1997, 126p.

. Conselho Nacional De Educação. Câmara De Educação Básica. Resolução no. 02, de 11 de setembro de 2001. Diretrizes nacionais para educação especial na educação básica. Brasília, 2001a.

. Ministério da Educação. Diretrizes nacionais para a educação especial na educação básica/ Secretária de Educação Especial - MEC. SEESP, 2001 b.

. Lei $\mathbf{n}^{\mathbf{0}}$. 10.436. Dispõe sobre a Língua Brasileira de Sinais (Libras) e dá outras providências. Diário Oficial da União, Brasília, 24 abr. 2002.

. Decreto $\mathbf{n}^{\mathbf{0}}$. 5.626. Regulamenta a Lei $n^{\circ}$. 10.436, de 24 de abril de 2002, que dispõe sobre a Língua Brasileira de Sinais (Libras), e o art. 18 da Lei nº ${ }^{\circ} 10.098$, de 19 de dezembro de 2000. Diário Oficial da União, Brasília, 22 dez. 2005.

. Lei 12.319. Regulamenta a profissão de Tradutor e Intérprete da Língua Brasileira de Sinais - LIBRAS. Diário Oficial da União, Brasília, 1º. set. 2010.

. Lei 13.146. Institui a Lei Brasileira de Inclusão da Pessoa com Deficiência (Estatuto da Pessoa com Deficiência). Diário oficial da União, Brasília, 6 jul. 2015.

BRATHWAITE, B.; SCHREIBER, I. Challenges for game designers. Boston: Charles River Media, 2008.

BROCHADO, S. M. D.; LACERDA, C. B. F.; ROCHA, L. R. M. Projeto de pesquisa: software glossário de informática com aplicação de libras e de tecnologia de captura de movimento 3D. Journal of Research in Special Education Needs, v. 16, n. s1. 905-908, 2016.

FORMOSO, D. de P. Professores surdos discutindo o currículo. In: THOMA, A. da S. KLEIN, M. (Org.). Currículo e avaliação: a diferença surda na escola. Santa Cruz do Sul: EDUNISC, 2009, 133p. Secretaria de Educação Especial - MEC/SEESP, 2001.

FRANCO, V. K. Adaptação Curricular (2007). Disponível em: http://caminhosdainclusao.blogspot.com.br/2007/08/adaptao-curricular.html. Acesso em 11 de novembro de 2017.

FREIRE, S. Um olhar sobre a inclusão. Revista Educação, v. XVI, n. 1, p. 5-20, 2008. 
FREITAS, O. Equipamentos e materiais didáticos. Brasília: Universidade de Brasília, 2007, $132 \mathrm{p}$.

GIL, A. C. (1946). Como elaborar projetos de pesquisa, 4. ed. São Paulo: Atlas, 2002.

HEREDERO, E. S. A escola inclusiva e estratégias para fazer frente a ela: as adaptações curriculares. Maringá, v. 32, n. 2, p. 193-208, 2010.

JESUS, A. R. Currículo e Educação: Conceito e questões no contexto educacional. - UEL - PUC São Paulo. (S/d).

KAWASE, E. M. Opinião de alunos surdos sobre vídeos em Língua Brasileira de Sinais como recurso didático. (Trabalho de Conclusão de Curso - Licenciatura em Educação Especial.) São Carlos: UFSCar, 2015.

LACERDA, C. B. F. Atendimento educacional especializado: necessidades educativas do sujeito surdo. São Carlos: UFSCar, s/d.

.C. B. F. O Intérprete educacional de língua de sinais no Ensino Fundamental: refletindo sobre limites e possibilidades. In: LODI, A. C. B.; HARRISON, K. M. P.; CAMPOS, S. R. L. ; TESKE, O. (Orgs.). Letramento e Minorias. Porto Alegre: Editora Mediação, 2002.

LACERDA, C. B. F.; LODI, A. C. B. Uma escola duas línguas: letramento em Língua Portuguesa e língua de sinais nas etapas iniciais de escolarização, 4. ed. Porto Alegre: Mediação, 2012.

LACERDA, C. B. F.; SANTOS, L. F. dos; CAETANO, J. F. Estratégias metodológicas para o ensino de alunos surdos. In: LACERDA, C. B. F. de; SANTOS, L. F. dos (Orgs.). Tenho um aluno surdo, e agora? Introdução à Libras e Educação de surdos. São Carlos: EDUFSCar, 2013, p. 185-200.

MEC. Estratégias para a educação de alunos com necessidades educacionais especiais / coordenação geral: SEESP/MEC; organização: Maria Salete Fábio Aranha. Brasília: Ministério da Educação, Secretaria de Educação Especial, 2003.

MEC. Tecnologias nas escolas. Brasília: Ministério da Educação, Secretaria de Educação Básica, s/d. 26 p.

MELETTI, S. M. F.; BUENO, J. G. S. Escolarização de alunos com deficiência: uma análise dos indicadores sociais no Brasil (1997-2006). In: REUNIÃO ANUAL DA ANPEd, 33, 2010, Caxambú. Anais... Caxambú: ANPEd, 2010, p. 1-17 (CD-ROM). 
NOGUEIRA, A.; CABELLO, J. Considerações sobre educação de surdos e tecnologias a partir da análise das estratégias de ensino de um professor surdo. Texto livre - linguagem e tecnologia. Belo Horizonte, v. 10, n. 1, p. 242-256, jan./jun. 2017.

OLIVEIRA, J. S.; STUMPF, M. R. Desenvolvimento de glossário de Sinais Acadêmicos em ambiente virtual de aprendizagem do curso Letras-Libras. Informática na Educação: teoria e prática. Porto Alegre, v. 16, n. 2, p. 217-228, jul./dez. 2013.

PLACHEVSKI, M. S. Sistema de Tecnologia Assistiva para captar a atenção de deficientes auditivos e surdos. Limeira, SP: [s.n.], 2014.

PRIETO, R. G. A construção de políticas públicas de educação para todos. In: PALHARES, M. S.; MARINS, S. C. (Orgs.). Escola inclusiva. São Carlos: EdUFSCar, 2002.

RAMOS, C. R. Livro didático digital em Libras: Uma proposta de inclusão para estudantes surdos. Revista Virtual de Cultura Surda, ed. 11. Editora Arara Azul, julho, 2013.

SÁ, N. R. L. Cultura, Poder educação de Surdos. Editora: Manaus da Universidade Federal do Amazonas, 2002.

SILVA, R. A.; RODRIGUES, R. S. Características de repositório educacional aberto para usuários de língua brasileira de sinais. Transformação, Campinas, 25(1): 65-79, jan./abr. 2013.

SKLIAR, Carlos. A Surdez: um olhar sobre as diferenças. Porto Alegre: Mediação, 2005.

SOUZA, D. M. M.; EGÍDIO, I. V. Avaliação dos docentes e futuros docentes, quanto ao conhecimento e utilização de mídias interativas nas práticas pedagógicas. HOLOS, Ano 32, v. 1, 2016.

WOHLMUTH, C. S. et al. Livro digital bilíngue para crianças surdas: uma análise na perspectiva do design visual de interface em tela. Design e Tecnologia, [S.1.], v. 4, n. 8, p. 31-38, dez. 2014. ISSN 2178-1974.

\section{LaRISSA DA COSTA}

Graduada em Licenciatura em Educação Especial pela Universidade Federal de São Carlos (UFSCar). Professora de Educação Especial, teve experiência como bolsista/pesquisadora na educação básica da rede pública por meio do Programa Institucional de Bolsas de Iniciação à Docência (PIBID, 2014 - 2017) e na Associação de Capacitação e Desenvolvimento Excepcional (ACORDE, 2016), atuando como professora colaboradora. 
Graduada em Fonoaudiologia pela Universidade Metodista de Piracicaba (2003), Mestre em Educação pela Universidade Metodista de Piracicaba (2007) e Doutora em Educação Especial pela Universidade Federal de São Carlos (2014). Professora Adjunta da Universidade Federal de São Carlos junto aos Cursos de Bacharelado em Tradução e Interpretação em Libras/Língua Portuguesa, Licenciatura em Educação Especial e também no Programa de Pós-Graduação em Educação Especial. Vencedora ( $1^{\circ}$.lugar) do 56 . Prêmio Jabuti (2014) pela Obra "Tenho um aluno surdo. E agora?"

Submetido em: 22-2-2018

Aceito em: 23-8-2018 